\title{
Misconceptions in legislative quality: an enlightened approach to legislative drafting
}

\author{
by Professor Helen Xanthaki
}

\begin{abstract}
The chapter summarises traditional teachings in legislative drafting, and identifies five misconceptions. Misconception 1: drafting conventions always lead to quality. But the phronetic nature of drafting prevents nomoteleia of drafting conventions. Misconception 2: Legislative quality rests in a vacuum. But the interconnectivity between policy, law, and legislative expression render their interdependence profound and critical. Misconception 3: legislative quality is undefinable. But effectiveness is a prominent definition of legislative quality. Misconception 4: effectiveness always leads to legislative quality. But legislation suffers from inherent limits: its interconnection and reliance to regulation, the limits of legislation as written communication, and the intrinsic aversion of users to legislative texts. Misconception 5: in view of the unsurpassable limits of legislative texts, legislative quality should not be pursued further. But there is hope ahead, such as the layered structure of legislative texts, the use of image in legislative texts, and the restructuring of the statute book as a whole.
\end{abstract}

\section{A. Introduction}

Legislative quality has been discussed and debated in great length, now more ever than before, with the recent EU focus on better regulation. The concept is commonly taken up by many disciplines, all with a different focus: lawyers talk about good and bad laws, linguists debate good and bad expression, economists discuss legislative efficiency, and political scientists seek good regulation. All angles are welcome but there still is one piece missing from the debate: the definition of legislative quality. What is it? How can it be achieved? Actually, can it be achieved? Without agreeing on the semantic field of the concept and its constituent referents, academic doctrine and professional praxis cannot benefit or advance.

From the legal perspective, legislative quality focused traditionally on legislative expression: words, terms, syntax and grammar lay at the heart of legislative drafting analyses. But, notwithstanding the importance of these choices, words on their own cannot nurture good 
laws. This is now evident in the UK, where language conflicts have been debated heavily and are seemingly resolved, at least for the time being until language and concept progress even further. However, plainer words and syntax has not managed to produce better laws.

The hypothesis of this paper is that legislative quality, and in consequence legislative drafting, is not about words and language. An enlightened approach to legislative drafting proposes that legislative quality is effectiveness of the legislative provision, which is measured by means of the text's ability to produce the desired regulatory results.

\section{B. A traditional concept of legislative quality}

The traditional methodology of legislative quality is introduced by Garth Thornton into five stages:

(1) Understanding the proposal.

(2) Analysing the proposal.

(3) Designing the law.

(4) Composing and developing the draft.

(5) Verifying the draft (Xanthaki, 2013, 145-162).

In practice, stage 1 involves the receipt and careful reading of drafting instructions compiled by the policy and legal instructing officers of the department that requests the drafting of legislation. Drafting instructions are data provided to the legislative drafter by the policy makers as a means of assisting the drafter to draft effective legislation within the parameters detailed by the policy makers of the government. They can be brief or detailed but they must provide the drafter with the necessary background information for the comprehension of all aspects of the political decision to proceed with legislation and the choice of the proposed legal means for the achievement of government policy. They must not take the form of a lay or rough draft law.

In the UK drafting instructions for primary legislation [government Bills] are instructed by Government Departments. The detailed policy (namely the results that a proposed Bill is intended to achieve) is worked out by the Administrators, with legal advice if necessary. Administrators are administrative civil servants who are responsible for policy and administration. Legal Advisers are based in Government Departments and are familiar with the 
legal framework (statutory and common law) under which the Department operates. Drafting instructions are prepared by a Legal Advisor, in close consultation with the Administrators. The Legal Adviser's main tasks are to work out what additions to, or changes in, the law are needed to give effect to the policy; to provide all the information the drafter needs in order to be able to draft the Bill (namely, to provide the drafter with proper drafting instructions; to discuss with the drafter any problems or difficulties arising out of the instructions; to ensure that every draft produced by the drafter is thoroughly examined by the Legal Adviser and the Administrators to see whether it achieves the desired results and to correct errors, wrong internal references etc. Above all, to make sure that the final draft really will achieve the main results desired. Detailed instructions prepared by Legal advisers within the Department are sent to the Office of Parliamentary Counsel (OPC). This is the concept of the "Bill Team".

Private Members' Bills do not, in principle, receive drafting support from the OPC. And delegated legislation is instructed and drafted within each Government Department.

Stage 2 involves the compilation of a legislative plan, also known as a legislative research report. It involves a brief or longer report on the basic elements of the drafter's response to the drafting instructions. It does not need to be complete, but a written sketch of the report or plan will assist the drafter to reap the advantages of the design of a legislative solution. The main advantage of a legislative plan is that it ensures that the end result of the legislation is what is expected from their policy makers: often matters of policy arise when the drafter attempts to transform an idea to a legislative text. Thus, the design acts as a bill's quality control. The legislative plan includes an analysis of the existing law (the mischief); an analysis of the necessity of legislation, a regulatory tool that can only be used as a solution of last resort where every other regulatory choice would not be effective; analysis of potential danger areas (constitutional, legal, practical); and an analysis of the practical implications of the legislative proposal, including an analysis of matters for which secondary legislation is likely to be needed to implement the draft law.

And so the legislative plan includes the following elements of content:

- Identification of the causes of the problematic behaviours behind the social need;

- Preliminary choices:

○ delimitation of the scope of the legislative solution: identification of the specific behaviour to be addressed and differentiation from other intertwined behaviours 
o history of the social problem as a means of understanding the elements for its regulation

○ comparative experiences as a means of identifying solutions offered elsewhere;

- Potential solutions to the problem by use of foreign experiences, academic opinion and departmental analyses included in the drafting instructions;

- Conformity inducing measures (A. Rose, 470) (punishments; civil damages or penalties; rewards; indirect measures);

- Description of the proposed solution;

- Analysis of the effectiveness of the proposed legislative solution;

- Analysis of the bill's probable cost and benefits;

- Identification of the monitoring and feedback systems (such as periodic evaluation of the effectiveness of the bill or sunset clause introducing limited life of the bill); and

- Justification of the bill's implementing provisions (such as the subjection of new duties to an existing agency or the creation of a new administrative, state or private agency; in the latter case a description of the new agency, appointment of members, and duties and powers of the agency must be included in the design of the legislative solution).

Stage 3 of the drafting process involves designing the law, namely structuring the legislative text in a manner that facilitates understanding, and consequently invites implementation. Bergeron (R. Bergeron, 1999) states that Bills must be arranged in a logical order. The provisions of the statute that are of a permanent nature precede those expected to have a limited life. The statute must be preceded by a table of provisions showing the headings and the section titles. The table of provisions is not part of the statute but is included to make it easier to consult. The statute is divided into parts only in those cases where the number of sections and the possibility of arranging them in categories constituting adequate conceptual units justifies this.

But the main source of doctrine when it comes to structure is Lord Thring, former First Parliamentary Counsel, who expressed his prioritisation of provisions in 5 rules (VRAC Crabbe, 1998, 148-150):

- Rule 1: Provisions declaring the law should be separated from, and take precedence of, provisions relating to the administration of the law: 
o "Convenience demands a clear statement of the law as distinct from its administration. One must know the law before questions of administration can arise hence the precedence of the statement of the law over its administration.

- Thus the advice is:

- state the law, and then

- state the authority to administer the law, and then

- state the manner in which the law is to be administered".

- An example is the setting up of the office of Coroners. It is advisable to establish the office of Coroner before stating the law of inquest. In such cases the law, as it were, emanates from the authority rather than the other way round.

- Rule 2: The simpler proposition should precede the more complex and, in an ascending scale of propositions, the less should come before the greater.

$\bigcirc$ Thus, in principle, assault should be provided for before aggravated assault.

- Rule 3: Principal provisions should be separated from subordinate provisions

○ The subordinate provisions should be placed towards the end of the Act, while the principal provisions should occupy their proper position in the narrative of the occurrence to which they refer. Principal provisions declare the material objects of the Act. Subordinate provisions are required to give effect to the principal provisions. They may deal with details, and thus complete the operation of the principal provisions.

- Rule 4: Exceptional provisions, temporary provisions and provisions relating to the repeal of Acts should be separated from the other enactments, and placed by themselves under separate headings.

- Rule 5: Procedure and matters of detail should be set apart by themselves, and should not, except under very special circumstances, find any place in the body of the Act.

○ This will explain the use of Schedules and sometimes of Regulations. In company legislation model Regulations could be set out in a Schedule. Procedural and administrative matters can also be delegated to subordinate legislation. Thus Parliament deals with the substantive law, and the procedural law is settled by departmental officials.

In practice, a Bill can include some of the following types of provisions (New Zealand Law Commission, 1996):

- Preliminary provisions 

- Long title
- Preamble
- Enacting clause
- Short title
○ Commencement
○ Duration/Expiry
- Application
- Purpose clause
- Definitions
○ Interpretation

- Principal provisions
- Substantive provisions
○ Administrative provisions

- Miscellaneous

- Offences and provisions ancillary to offences such as time limit for prosecution, continuing offences, offences by corporations, and vicarious responsibility

- Miscellaneous and supplementary provisions such as evidentiary provisions, a power to make subordinate legislation, service of notices, powers of entry and search, seizure and arrest.

- Final Provisions

- Savings and transitional (these may also be placed in a schedule if they are long)

○ Repeals

- Consequential amendments (these may be placed in an annex especially if the repeals and consequential amendments are numerous and can conveniently be presented in a tabular form)

○ Schedules

Modern legislative drafting theory, as part of the plain language movement demanding plainer legislative texts, urges legislative drafters to bare the text from preliminary provisions and, following the lessons learnt from media studies and advertising, to start as early as possible with the regulatory message that the government is trying to convey to citizens. Legislation is a form of communication: it involves, in its most part, the expression of a prohibition of citizen activity: after all, citizens can do whatever they wish, unless law prohibits it. And so the pursuit 
of modern drafters is to share that message with their audience (the users of the legislation) in a manner that gets them to get heard loud and clear.

And so, the traditionally long list of preliminary provisions is being cut shorter and shorter. The long title, namely the description of the manner in which the law is reformed, remains at the very top of modern legislative texts. But the role of the preamble is diminished to a cosmetic one in the case of archaic or ceremonial laws, or to a transitional one in the case of the confirmation of the legal basis of the law and the observance of the constitutional stages of the legislative process in newer or weaker democracies. The enacting clause remains, as a constitutional requirement without which the text lacks legitimacy. The short title remains as a means of reference to the law in the index of the statute book. But commencement, duration, expiry, application, and interpretation provisions are now transferred to the final provisions part. Similarly, definitions are finding their way either in final provisions or, preferably, in schedules at the back of the legislative text. And what seems to be making a surprise revival is purpose clauses, which may have been persecuted to extinction in the past but now are invited back as objectives clauses including measurable and concrete criteria for the effectiveness of the legislation in regular post-legislative scrutiny cycles.

Substantive provisions introduce rights, powers, privileges, and immunities of persons to be benefited or regulated. These provisions are drafted as prescriptions, prohibitions, regulations or combinations. Statutory corporations are introduced with care: their powers can only be those awarded to them by statute and those which are necessary for the completion of the purpose of incorporation (even if they are not directly awarded to them by statute). Licensing and registration provisions cover the appointment of a licensing authority, the object of its activity, the manner of application for the licence, the sanctions for breach of the obligation to obtain a licence or fraudulent behaviours in the procedure, appeals procedures, inspection issues, subsidiary legislation and any transitional regimes.

Final provisions include savings, transitional provisions, repeals and consequential amendments, and schedules. Savings provisions preserve or "save" a law, a right or privilege that would otherwise be repealed or cease to have effect. In other words, saving provisions keep in being laws, rights or obligations that might otherwise disappear when an existing law is repealed. Transitional provisions are necessary to enable a smooth transition to be made between the existing law and the new law; they tie up the loose ends which would otherwise be left dangling. Although savings and transitional provisions are often confused, they are two different 
species and should carry separate headings. Savings provisions do not relate to time: they simple preserve a circle of persons or activities from the field of application of the new regime; they are long term provisions. Transitional provisions focus on regulating for the short term issues that continue to fall within the field of application of both the old and new regime but the regulation changes with the new regime. They are short term provisions that regulate the transition between the old and the new regime for the same class of subjects, or objects, or activities.

Repeals are deletions of provisions or Acts from the statute book. They must be introduced expressly to avoid confusion. Implied repeals, namely repeals that come about de facto but have not been expressly introduced in the legislative text are an anomaly of drafting and cannot be tolerated. At the end of the day, repeals are a drafter's not a judge's job. Repeals can be simple, where legislation is no longer required (unusual in practice); combined with reenactment, where a new enactment consolidates the law that is essentially unchanged; or combined with replacement, where existing legislation is being remolded to meet new circumstances in different ways (the most usual circumstance in practice). It is still questionable whether amending Acts or subsidiary legislation deriving from the repealed Act need to be expressly repealed. From a constitutional and statutory interpretation perspective, they do not need to be repealed, as they will have merged with the principal Act on coming into force. From that point of view, express repeal of such an amending Act or provision would be required only in the rare instance that it had not yet come into force at the date of proposed repeal. But from a drafting perspective where clarity and certainty in the law lies at the heart of the matter, express repeal even of delegated legislation is crucially helpful to the user, and must be upgraded to best practice.

Schedules are provisions attached to the main text of the law, hanging from a substantive provision within the text. They free the main body of an Act from a possible charge of untidiness (Crabbe, VRAC, 1998, 145-147). The use of schedules can make a substantial contribution to effective communication by clearing away procedural and other distinct groups of provisions to schedules in order to present the main provisions of the statute prominently and in a less cluttered package. The Keeling Schedule is a device that 'sets out the wording of the enactment, indicating by bold type the changes proposed' (Bennion, 1990, 56). It is only used where the changes made by the Bill in the previous enactments are exclusively textual amendments or repeals. The Keeling technique not only shows, in the Schedule how the law will look once it is amended, but also makes clear, in the text of the Bill itself, how the law is being amended.' (Renton report, 13.22) 
Stage 4 sees the actual drafting of the text. The drafting of substantive provisions requires application of the rules for words and grammar that are considered to serve the intelligibility of the text. Drafters use words that are plain, clear, well understood, and unambiguous. Bad practices include the use of unnecessary words; the use of the same word or phrase in different contexts; synonyms; jargon; passive voice; plural; gender specific language; archaic terms (such as "said" as an adjective); the use of "shall" to express a duty, obligation or prohibition. Best practice includes the use of the present tense and indicative mode; the use of "may" to express a power or privilege, and "must" or present tense to express the imperative mode; and gender-neutral language. Best practice also encourages good presentation techniques. Drafters lay out the draft so that, when printed, the text is are easy to work with. And so encouraged is the use of plenty of "white space" (i.e. the text is not densely packed); short sentences, and paragraphing to display component parts; a consistent system for numbering articles, paragraphs and tabulations; and visual aids, such as formulae, maps and diagrams.

Stage 5 involves the verification of the legislative text. Drafts need to be verified as a means of achieving quality. Verification takes place internally, namely within the drafting team, and externally, namely by other interested Ministries and affected agencies. Scrutiny of the legislative text should be a continuous process throughout the drafting, particularly to improve its clarity and to check its practicability. Best practice calls for each version of a draft should be subjected to scrutiny of legal form, clarity and comprehensibility; and at the end of drafting, the final version of the law must be scrutinised on a wider range of matters, including a series of legal verifications. Checks on legal form, clarity and comprehensibility includes controls that the conventional requirements as to the form, structure and presentation of legislation have been followed; the language of the legal provisions follows standard language usages and is easily comprehended and free of ambiguity; the ordering of the provisions in the law is logical and facilitates its use; terms used in the law are followed consistently throughout the law and that unnecessarily legalistic or archaic terms are not used. Legal verification checks include constitutional and legal compliance controls.

\section{An enlightened approach to legislative quality (Xanthaki, 2011, 18-26)}

The drafting conventions detailed in the traditional approach are often viewed as sacred traditions in legislative drafting: principles that are followed blindly, without bothering with the identification of their theoretical roots. This makes their replication and accurate application 
in new cases of legislative dilemmas either religiously bound to past precedent or haphazard in the choice of their prioritisation against other relevant conventions.

In fact, drafters debate over the existence of conventions at all (Xanthaki, H, 2008, 1). Common lawyers deny the existence of conventions and view legislative conventions as traditional wisdom of drafters past, followed simply because they once seemed to work well. Since to them drafting is a pure form of art (Scharffs, B G, 2001, 2339) or a quasi craft (Nutting, C, 1955, 76), creativity and innovation lies at the core of the task. Rules and conventions bear relative value, and the main task of the drafter is to learn the craft from those with more experience. For the civil lawyers drafting conventions are binding. Since drafting is a science or technique, conventions are formal rules that, if applied correctly, lead to legislative quality repeatedly.

\section{C1. And here lies misconception number 1: Legislative quality comes via the application of a specific legislative convention.}

Conventions do exist and indeed they are important, because they have worked in the past. But they are not shackles in the drafter's feet. Where they benefit legislative quality, they are an aid. Where they prevent legislative quality, they bow down to alternative choices.

This is supported by the phonetic theory of legislative drafting. For us phroneticists, legislative conventions cannot share the universality and infallibility of science. Gravity applies everywhere, and at all times. Law is different. "All law is universal but about some things it is not possible to make a universal statement which will be correct... the error is not in the law nor in the legislator but in the nature of the thing" (Aristotle). Using the term "shall" may be an abomination for those of us who avoid ambiguity, but it would be rather misguided to reject the use of the term rigidly: it may well be that "shall", ambiguous as it is, would be understood better, and therefore be more effective, in amendments of archaic laws where the term is used repeatedly to signify "must"; here, using the term "must" in conjunction with the existing "shall" would create the legitimate impression to the user that the meaning of "shall" and "must" is somewhat different.

But the relativity and flexibility of drafting conventions does not necessarily equate to anarchy. Of course, its rules are not rigid, but they are present. The use of synonyms is a principle by which drafters abide, mainly to serve clarity. There may be exceptions to all rules of drafting, but this does not mean that there are no rules. And these rules carry with them a 
degree of relevant predictability, since the latter is one of the six elements of theory (Flyvbjerg, B, 2001, 39).

Drafting as phronesis is "akin to practical wisdom that comes from an intimate familiarity with contingencies and uncertainties of various forms of social practice embedded in complex social settings" (Schram, S F, and Caterino, B, 2006, 8). In other words, the art of drafting lies with the subjective use and application of its science, with the conscious subjective Aristotelian application and implementation of its universal theoretical principles to the concrete circumstances of the problem Eskridge, W, 1990, 635). Phronesis supports the selection of solutions made based on informed yet subjective application of principles on set circumstances (Engle, E, 1008, 4). Phronesis is "practical wisdom that responds to nuance and a sense of the concrete, outstripping abstract or general theories of what is right. In this way, practical wisdom relies on a kind of immediate insight, rather than more formal inferential processes". (Rideout, C, 2008, 75)

So the drafter's task simply involves the choice of the appropriate rule or convention that delivers the desired results within the unique circumstances of the specific problem at any given time. In other words, the drafter needs to be aware of the multitude of often clashing rules and conventions; the drafter needs to identify the most relevant set of circumstances applicable to the problem; and the drafter needs to have the theoretical knowledge and practical experience to promote the rule or convention that best delivers under the mostly unique circumstances of the problem. In other words, as drafting entails both elements and art and elements of science, the drafter's task entails both identification of all relevant circumstances and rules; and promotion of the most appropriate rule.

Phronesis offers an excellent theoretical framework for legislative quality outside of drafting conventions. Since these are existent but relative, legislative quality cannot be based on them. In other words, the choice and application of a legislative convention does not lead to good law.

If the current lists of drafting rules and conventions cannot adequately serve as elements of quality in legislation, how can one define the concept of quality? It has now become obvious that this is not a matter of agreeing or disagreeing in the components of an empirical or technical definition. If the fault lies with the subjective and inexorable nature of drafting rules, then we need to review our approach to quality by seeking its definition on a non-technical, non-empirical nature. 


\section{C2. Here lies misconception number 2: Legislative quality rests in a vacuum}

If one sees legislation as a tool for regulation, then drafting becomes simply part of the legislative process, which in turn is part of the policy process. (Stefanou, C, 2008, 321, 323) The object of a policy process is the promotion of a government policy, or from asocial perspective the regulation of a citizens' activity. A good law simply contributes to the achievement of the policy that it serves. In other words, the government of the day seeks to implement its policy by use of the policy process. During the policy process, legislation may be selected as the optimum tool for implementation: if this is the case, the legislative process comes into play. It is within the legislative process that drafters undergo each one of Thornton's five stages of drafting and draft legislation. To retrace this journey backwards, the drafter drafts, the legislature passes laws, and thus the government executes the programme of policies with which it has been elected to govern.

If one takes this holistic picture of legislation as a tool for regulation into account, identifying the goal of the drafter as achieving "quality in legislation" is a rather short sighted and narrowly focused approach. In application of Stefanou's scheme on the three processes, drafters can only aim to perform well in their little, albeit crucial, part in the application of governmental policy better expressed as regulation. (Xanthaki, H, 2011, 75)

As a law on its own cannot produce adequate regulatory results without synergy from the other actors of the policy process (Chamberlain, J P, 1931, 243), a good law is one that, with synergy, is able of producing the regulatory results required by policy makers (Mader, L, 2001, 126). A good law is one that is capable of leading to efficacy of regulation. A good law is an effective law. And ultimately, quality in legislation is effectiveness. Effectiveness is the criterion that drafters use when selecting the most appropriate drafting rule for the problem before them. This qualitative definition of quality in legislation respects and embraces the subjectivity and flexibility of both drafting rules and conventions and, ultimately, of phronetic legislative drafting. (Xanthaki, H, 2010, 111)

\section{C3. Here lies misconception number 3: Legislative quality is not definable}

In a search for a qualitative definition of quality in legislation, one can resort to functionality. If legislation is a mere tool for regulation, and indeed a tool only to be used if everything else will fail (Weatherhill, S, 2007, 19), then a good law is simply a law that, if it enjoys support and cooperation from all actors in the legislative process (Chamberlain, $\mathrm{J} \mathrm{P,} \mathrm{1931,} \mathrm{243),} \mathrm{is} \mathrm{able}$ 
of producing the regulatory results required by policy makers. In other words, a good law is simply a law that is capable of achieving the regulatory reform that it was released to effectuate or support (Mader, L, 2001, 126). A good law is one that is capable of leading to efficacy of regulation. There is nothing technical at this level of qualitative functionality: what counts is the ability of the law to achieve the reforms requested by the policy officers. And, in view of the myriad of parameters that are unique in each dossier, there are no precise elements of quality at this level. If anything, this qualitative definition of quality in legislation as synonymous to effectiveness respects and embraces the subjectivity and flexibility of both drafting rules and conventions and, ultimately, of phronetic legislative drafting.

But does the qualitative functional approach to the definition of quality in legislation signify that everything goes? The answer is of course negative: legislative drafting is phronetic, it is not art. In phronetic legislative drafting, one must be able to identify basic principles that, as a rule, can render a law good. Cost efficiency, clarity, precision, and unambiguity are such principles: when applied, at least in the majority of cases, they lead to good laws. But, at the end of the day, each dossier carries subjective choices for the drafter, choices made on the basis of the ultimate functional test: effectiveness. What makes a law a good law therefore is the ability of the drafter to use the criterion of effectiveness consciously and correctly. What is correct application of the effectiveness criterion is a matter of debate and deliberation within the drafting team: after all, even drafters are human. Perhaps this is the beauty of a drafter's trade: there are no safety nets, no walls to hide one's nudity before the cruel sword of the end result.

C4. Here lies misconception number 4: Effectiveness always leads to quality (Xanthaki, H, 2013b, 128-143)

Effectiveness has opened the ground to great innovations in legislative drafting. Many of those are present in the laws of the UK, such as gender neutral drafting (Statement of the Leader of the House of Commons on 8.3.07), the use of explanatory memoranda (http://www.parliament.uk/site-information/glossary/explanatory-memorandum), the placement of definitions at the end and probably in a schedule (OPC, 2010, 31), the increased use of Keeling schedules (House of Lords Select Committee on Constitution, Fourteenth Report, 2004， http://www.publications.parliament.uk/pa/ld200304/ldselect/ldconst/173/ 17302.htm, chapter 4,89 .) to name but a few. The increasing use of visual aids in legislation, such as the Australian depiction of the coloured Australian flag in the schedule of the relevant 
Act, which also includes a clickable link to the sound of the national anthem, is a tool for clarity and unambiguity in the introduction of diagrams, pictures, and songs in legislation. The increasing use of explanatory materials in the introduction of legislative drafts in the Commonwealth responds to the need for additional clarifications of the policy and text, which are deemed too detailed to be accommodated in the modern, dry, short style of legislation. The condemnation of general implied consequential amendment clauses in Africa is addressed by exhaustive lists of express direct and consequential amendments, including those related to delegated legislation. The technique of restatement in Ireland is a direct response to the former ambiguity invited by detailed, direct amendments of legislation, which rendered the text unapproachable to the users. The replacement of mosaic laws via the New Zealand's Miscellaneous Act that breaks down into its constituting parts, which upon passing find their place in the precise Acts under amendment, constitutes a pursuit for a mechanism for clarity in the statute book. The introduction of primary and delegated legislation together as a whole regulatory package submitted before the Kenyan Parliament signifies an innovative approach to the constitutional and drafting deficiencies of modern overflowing of delegated legislation. The EU's frequent use of sunset clauses coinciding with the end of the cycle of monitoring of the legislative text is a unique technique forcing the regulators to re-consider the necessity and effectiveness of the legislation and to act in order to avoid, if necessary, the end of life of the legislative text. The recent calls for a return of purpose or objectives clauses in legislation, provided that the latter list the factors to be taken into account when tangible and measurable effectiveness is monitored at the pre and post-legislative scrutiny exercises are a wonderful mechanism to express the link between policy choices and legislative expression, and to address regulation as a full circle beginning with policy formulation and ending with the juxtaposition of legislative objectives against the achievement of tangible policy aims. And finally, the placement of definitions at the end of the legislative text, perhaps even in a schedule, is a fantastic attempt to bare the legislative text from anything that detracts from the regulatory message and its placing at the forefront of legislative communication with the user.

But all these wonderful steps towards effectiveness stumble to the inherent limits of legislation as a product.

\section{C4.1. Legislation as a tool for regulation}

Legislation is simply a tool for regulation, namely a tool in the process of putting government policies into effect to the degree and extent intended by government. In other words, legislation 
is one of the many weapons in the arsenal of governments for the achievement of their desired regulatory results (Flueckiger, A, 2004, 159), which in turn is the prevalent measure of policy success (Staem, N, 2006, 7). The regulatory tools available to government vary from flexible forms of traditional regulation (such as performance-based and incentive approaches), to coregulation and self-regulation schemes, incentive and market based instruments (such as tax breaks and tradable permits) and information approaches (OECD, 2002). But legislation remains one of the most popular regulatory tools.

So what is legislation attempting to achieve and by what means? The diagram below visualises these goals and their hierarchy (Xanthaki, 2008).

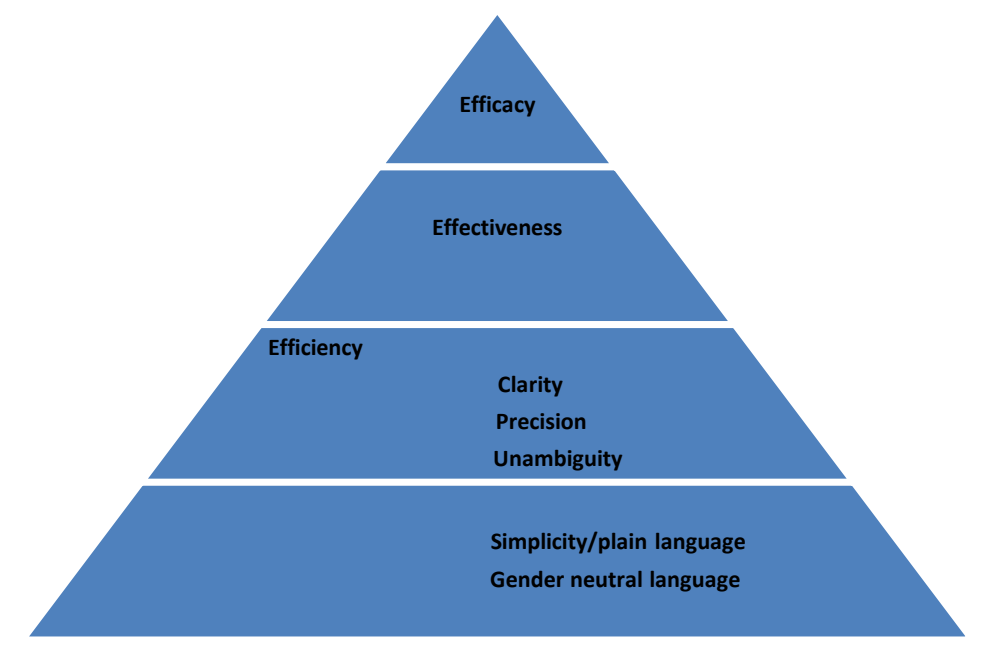

Starting with efficacy, this is the extent to which regulators achieve their goal (Mousmouti, M, $2012,191)$. The term is often used interchangeably with effectiveness, especially by experts outside the field of legislative studies (Flueckinger, A, 2007, 83). But the concept of the main regulatory goal remains the achievement of the desired regulatory results. However, achieving the desired regulatory results is not a goal that can be achieved by the drafter alone (Chamberlain, J P, 1931, 243): legislation requires a solid policy, appropriate and realistic policy measures for its achievement, cost efficient mechanisms of implementation, and ultimately user willingness to implement and judicial inclination to interpret according to legislative intent.

The drafter's limited possible contribution to efficacy is effectiveness (Timmermans, C, 1997, 1229, 1236-1237), defined as the extent to which the observable attitudes and 
behaviours of the target population correspond to the attitudes and behaviours prescribed by the legislator (Mader, L, 2001, 119, 126); or "the fact that law matters: it has effects on political, economic and social life outside the law - that it, apart from simply the elaboration of legal doctrine" (Snyder, F, 1993, 19, 19); or a term encompassing implementation, enforcement, impact, and compliance (Teubner, G, 1987, 54); or the degree to which the legislative measure has achieved a concrete goal without suffering from side effects (Muller, G, and Uhlmann, F, 2013, 51-52); or the extent to which the legislation influences in the desired manner the social phenomenon which it aims to address (Jenkins, I, 1981, 180; Cranston, R, 1978-1979, 873, 875); or a consequence of the rule of law, which imposes a duty on the legislator to consider and respect the implementation and enforcement of legislation to be enacted (Voermans, W, 2009, 230); or a measure of the causal relations between the law and its effects: and so an effective law is one that is respected or implemented, provided that the observable degree of respect can be attributed to the norm (Mousmouti, M, 2012, 200). If one attempts to use all of the elements of these enlightened definitions of effectiveness, one could suggest that effectiveness of legislation is the ultimate measure of quality in legislation (Xanthaki, H, 2008, 6), which reflects the extent to which the legislation manages to introduce adequate mechanisms capable of producing the desired regulatory results. In its concrete, rather than abstract conceptual sense, effectiveness requires a legislative text that can (i) foresee the main projected outcomes and use them in the drafting and formulation process; (ii) state clearly its objectives and purpose; (iii) provide for necessary and appropriate means and enforcement measures; (iv) assess and evaluate real-life effectiveness in a consistent and timely manner (Mousmouti, M, 2012, 202).

And so this is the first and main inherent limit of legislation. As a mere expression of the regulatory agenda, legislation inevitably relies on the soundness of the policy goals and regulatory aims set by regulators. Legislation requires a constitutionally, legally, ethically, and democratic (in the sense of acceptable by the majority) policy aim pursued by equally constitutional, legal, ethical, democratic, and cost efficient means to achieve it. Moreover, it relies on the intent of users and interpreters to comply with it. Of course, this interdependence of policy, regulation, legislation, and implementation works both ways: good legislative expression can accentuate the logic of the policy, can clarify the choice of regulatory tools, and can ultimately incite implementation. But in the same way that efficacy requires legislative facilitation of regulatory success, it also requires the synergistic contribution of all parts and actors of the drafting process as part of the legislative process, which in 


\section{C4.2. Legislation as written communication}

Added to the lack of its ultimate control over efficacy, legislation is further limited by the means by which it can pursue efficacy. The diagram above expresses that effectiveness can be achieved by means of clarity, precision, and unambiguity. And that these can be enhanced by the use of plain language and gender neutral language. Legislation aims to communicate the regulatory message to its users as a means of imposing and inciting implementation. It attempts to detail clearly, precisely, and unambiguously what the new obligations or the new rights can be, in order to inform citizens with an inclination to comply how their behaviour or actions must change from the legislation's entry into force. The receipt of the legislative message in the way that it was sent by the legislative text is crucial for its effectiveness and, ultimately, for the efficacy of the regulation that the text expresses.

Plain language aims to introduce principles that convey the legislative/regulatory message in a manner that it clear and effective for its audience. Plain language encompasses all aspects of written communication: words, syntax, punctuation, the structure of the legislative text, its layout on paper and screen, and the architecture of the whole statute book as a means of facilitating awareness of the interconnections between texts. And so plain language begins to kick in during the analysis of the policy and the initial translation into legislation, with the selection and prioritization of the information that readers need to receive. It continues with choices related to structure during the selection and design of the legislative solution, with simplification of the policy, simplification of the legal concepts involved in putting the policy to effect, and initial plain language choices of legislative expression (for example, a decision for direct textual amendments combined by a Keeling schedule, or a repeal and re-enactment when possible). Plain language enters very much into the agenda during the composition of the legislative text. And remains in the cards during the text verification, where additional confirmation of appropriate layout and visually appeal come into play. And so plain language extends from policy to law to drafting. The existing concept of plain language relates to a holistic approach to legislation as a text, as a printed or electronic image, and as part of the statute book.

But the blessing of this ambitious mandate constitutes the weakness (or is it limit?) of plain language as a main contributor to clarity, precision, unambiguity, effectiveness, and ultimately efficacy. Plain language cannot be distilled to the set of rules that must always be followed: the rules are relative and directly affected by the precise audience of the specific legislative communication: mens rea is easily understood by a legal audience but of course it 
is an unfamiliar term to audiences without legal sophistication. The relativity of plain language is expressed by the recent replacement of objective simplification as its goal with the more subjective easification. Easification requires simplification of the text for its specific audience, and thus requires an awareness of who the users of the texts will be, and what kind of sophistication they possess. And it must do so in a single document: possible clashes between various instruments at various levels would incite uncertainty in the law, thus making it ineffective anyway.

Answers to these questions were simply not present for legislation until very recently. It was widely accepted that legislative communication involved the drafter (who, at least in the UK, is a trained lawyer with drafting training and experience) and the generic user (who can be anything from a senior judge to an illiterate citizen of below average capacity). The inequality in the understanding of both common terms (whichever they may be) and legal terms renders communication via a single text a hopeless task. And this is precisely the second limit of legislation: communication from a trained and highly experienced lawyer to a wide circle of possible audiences with vast diversion of general and legal sophistication is simply an impossible task. Much more so if this is attempted by means of a single written text. This deprives the communication sender from the opportunity to gauge reception and make amends by means of further clarification where needed, or by means of intonation or even gestures that are simply not available in written communication.

It is this inherent limit of legislation that has led to the supplementing of the legislative text by parliamentary interpretation, policy guidance, explanatory materials, and annotations. What these fail to take into account though is the change in user attitudes: at a time where users are used to using the internet to receive direct answers from the original sources of communication instead of relying on intermediary professionals, legislation is used as a direct source of answers to questions related to the text. This is proven by the 2,000,000 users per month of the UK government's free electronic legal database. But more about this a bit later. For now, it suffices to identify the second limit of legislation, its presentation in the form of written communication.

C4.3. The intrinsic aversion of users to legislative texts: https://www.gov.uk/government/publications/when-laws-become-too-complex/when-lawsbecome-too-complex 
The last limit of legislation relates to a phenomenon observed and recorded by the Office of Parliamentary Counsel: users' aversion to legislation. This takes the form of perceptions of over-complexity or negative perceptions. The OPC is not unique in identifying this as an issue: the basis of the plain language movement lies with legislative complexity with reference to words, structure, and placement within the architecture of the statute book.

In other words, users of diverse legal sophistication are overwhelmed by the volume and complexity of legislation. They find it difficult to understand the terminology used with the text, the structure of the Act itself, and the interconnection of the Act with other primary and secondary legislative texts and the statute book as a whole. What users find intimidating is not just the words themselves (one could argue that the simplification of words has come a very long way) but the context of the legislative message within the many provisions of the same Act, and within the labyrinth of relevant primary and secondary sources of law.

Negative perception of legislation describes the phenomenon of citizens' attribution of more complexity to legislation than it actually is. Navigation between pieces of legislation is often the problem. Users also appear to find it difficult to find reliable explanatory information and relevant guidance.

This is the third limit of legislation: it is an inherent living and ever evolving organism of complexity whose understanding requires context, both conceptual and historical. In other words, legislation needs to be accessible in a manner that allows the user to understand what the law (rather than the specific legislative text) is, at any given moment in time.

\section{C5. Here lies misconception number 5: There is nothing more to be done for legislative quality}

One could argue, rather persuasively, that these are unsurpassable limits of legislative texts. They form part of the characteristics of legislation as a product. And one could resign to their prevalence. But that would means resigning to the ineffectiveness of legislation, or its inappropriateness as a regulatory tool. This could not be further from the truth. Having identified its measure of excellent, and the means by which legislation can achieve it, the study of legislation must now turn to its weakness and an assessment of a method that can reduce the effect of these inherent limits. Until very recently, this was impossible. What can facilitate communication is the identification of the possible precise users of the specific legislative text: 
identifying who the users of the text will be allows the text to 'speak' to them in a language that tends to be understood by them. Until now identifying the users was a hypothetical and rather academic exercise. Recent empirical data offered by a revolutionary survey of The National Archives in cooperation with the Office of Parliamentary Counsel have provided much needed answers. The survey of 2,000,000 samples of users of www.legislation.gov.uk has identified at least three categories of users of legislation: lay persons reading the legislation to make it work for them, sophisticated non -lawyers using the law in the process of their professional activities, and lawyers and judges. In more detail in the UK there are three categories of users of legislation:

a. Non-lawyers who needs to use legislation for work, such as law enforcers, human resources professionals, or local council officials; the 'Mark Green' of the survey represents about $60 \%$ of users of legislation;

b. Lay persons who seeks answers to questions related to their personal or familial situation; 'Heather Cole' represents about $20 \%$ of users of legislation; and

c. Lawyers, judges, and senior law librarians; the 'Jane Booker' persona represents about $20 \%$ of users of legislation.

The significance of the survey cannot be understated. The survey, whose data relate to users of electronic versions of the free government database of legislation only, destroys the myth that legislation is for legal professionals alone. In fact, legal professionals are very much in the minority of users, although their precise percentage may well be affected by their tendency to use subscription databases rather than the government database, which is not annotated and often not updated. Whatever the exact percentages of each category are, there is significant empirical evidence that in the UK legislation speaks to three distinct groups of users, whose legal awareness varies from none, to some, to expert. But is the legal awareness of the users the only parameter for plain language as a means of effective legislative communication?

Pitching the legislative text to the 'right' level requires an additional consideration. Having realised which are the rough profiles of the audience, the next parameter for plain communication is the topic of the legislative text. Legislative texts are not all aimed at the same readers. Their primary audience varies. For example, the main users of rules of evidence the drafter are probably judges and lawyers. So the language and terminology used can be 
sophisticated: paraphrasing the term 'intent' with a plain language equivalent such as 'meaning to' would lead the primarily legal audience to the legitimate assumption that the legislation means something other than 'intent' and would not easily carry the interpretative case-law of 'intent' on to 'meaning to'. And so rules of evidence can be drafted in specialist language, albeit with a caveat: a primarily legally sophisticated audience cannot serve as a 'carte blanche' for legalese, since non-lawyers may need to, and in any case must, have access to the legislation too. As audiences become more specialized and more educated in technical areas, they expect texts that are targeted to their particular needs. Moreover, since accessibility of legislation is directly linked to Bingham's rule of law, passing inaccessible legislation under the feeble excuse that its primary audience possesses legal sophistication is not easily acceptable. And so there is an argument for either the continued use of legal terminology or for the provision of a definition of the new plain language equivalent referring to the legal term used until now.

But how 'plain' must legislation be? Even within the 'Heather Cole' persona there is plenty of diversity. There is a given commonality in the lack of legal training, but the sophistication, general and legal, of Heather Coles can range from a fiercely intelligent and generally sophisticated user to a rather naïve, perhaps illiterate, and even intellectually challenged individual. Which of those Heather Coles is the legislation speaking to? It certainly is not the commonly described as 'the average man on the street'. To start with, there are also women on our streets, and they are users of legislation too. And then, why are the above or below averages amongst us excluded from legislative communication? Since effectiveness is the goal of legislative texts, should legislation not speak to each and every user who falls within the subjects of the policy solution expressed by this specific legislative text? This includes the above average, the average, and the below average people.

This is a rather revolutionary innovation. Identifying the users of legislation has led to not one but two earthquakes in legislative studies: yes, the law does not speak to lawyers alone; but the law does not speak to the traditional plain language 'average man'. If applied in practice, this new knowledge will change the way in which legislation is drafted. First, legislative language can no longer be gauged at legal and regulatory professionals. Although great advances have already taken place, legislation now tends to be pitched to 'Mark Green': further simplification to the benefit of 'Heather Cole' needs to take place with immediate effect. The Office of Parliamentary Counsel are working on this: for example, the term 'long title' referring to the provision starting with 'An Act to...' is now replaced by the term 'introductory text' as 
standard in the tables of arrangement found on all Acts in www.legislation.gov.uk. Similarly, there is talk of switching from 'commencement' to 'start date', as user testing has shown that commencement is puzzling to non-lawyers. The Guidance to drafting legislation reflects the UK government's commitment to legislating in a user friendly manner.

But more can be done. It is time to look at legislation with an innovative lens in order to identify initiatives that can address its inherent limits.

\section{C.5.1. Alternatives: delimit the limits}

Having established the concept of effectiveness as synonymous to good legislation, and the new holistic mandate of plain language in legislation, and armed with the new empirical data offered by TNA and OPC, let us discuss further possibilities. I have identified three blue sky mechanisms for better law. They respond to the limits of legislation: the layered structure promotes a three tier structure for legislative texts each addressed to each of the three user groups; the typography inspired presentation and layout responds to the need to bring to light the main regulatory messages in legislation; and the interactive electronic statute book highlights the interconnectivity between legislative texts within the statute book as a whole.

\section{a. The layered approach to structure}

Currently legislative texts are structured in application to Lord Thring's Five Rules of Drafting (Thring, Lord, 1902) that offers precedence to provisions declaring the law versus provisions relating to the administration of the law; to simpler versus the more complex proposition; and to principal versus subordinate provisions. Exceptional, temporary, and provisions relating to the repeal of Acts, and procedure and matters of detail should be set apart. But there is much scope for blue sky innovation by use of the layered approach. The rationale behind the modern approach lies with the logical sequence of provisions within the text, which reflects logic, and philosophical and linguistic approaches to language and thought. This basis has now been overcome by the crucial evidence on the three user groups for legislation. Heather Cole, Mark Greene, and Jane Booker are diverse users that require diverse pitches of the legislative text. Speaking to all three of them at the same time is a rather complex, for some impossible, task. Introducing three versions of the same legislative text is a possibility but it is a recipe for disaster on such a diverse range of grounds, moral, ethical, constitutional, practical: rule of law, issues of interpretation between versions, identifying which version corresponds to each user, 
using that version as opposed to the one selected by the user, who subjects each user to their corresponding persona, ethical and moral consequences of the application of a diverse version for each user. And the parallel existence of three different texts could be counter-productive: users currently choose to use the complex but official legislative text over any of the many interpretation aids offered by government. If the plethora of attractive user friendly manuals and policy documents are shunned in favour of legislative texts, what makes it probable that users will go to the simple Heather Cole text as opposed to the legal Jane Booker one that reflects users' perception of legislation? And so remaining with a single text is really the only option. But this is exactly what has imprisoned legislative drafters in the struggle for simplicity within legislative texts.

It is now possible to see that each user group has its individual requirements for legislative information that are distinct from those of the other user groups. Identifying the needs for legislative information for each user group at a provision, rather than text, level would allow drafters to imitate oral communication, and pitch the legislative text to specific abilities and requirements. Drafters of legislative texts can now begin to think what regulatory or legal message is relevant to each group, and structure the text accordingly.

The layered approach promotes the division of legislation into three parts, corresponding to each of the three profiles of legislative users. Part 1 can speak to lay persons: the content is limited to the main regulatory messages, thus conveying the essence of law reform attempted by the legislation, focusing gravely on the information that lay persons need in order to become aware of a new regulation, to comply with new obligations, or to enjoy new rights. Part 2 can speak to non-legally trained professionals who use the legislation in the course of their employment. Here one can see scope for further detail in the regulatory messages introduced, and for language that is balanced [technical, yet approachable to the professionals in question]. Part 3 of the legislation can then deal with issues of legislative interpretation, issues of procedure, and issues of application, in a language that is complex but not quite legalese, as there is nothing to prevent all groups from reading all parts.

The layered approach is revolutionary, as it shifts the criterion for legislative structure from the content and nature of provisions to the profile of the users. It switches on a usercentred structure, thus promoting both a link between policy and its effecting legislative text but also enhancing and personalising the channel of communication between drafters and users. And it applies and reflects the modern doctrine of contextualism in language and philosophy. 
But it cannot be viewed as a complete departure from tradition, as it continues to apply Lord Thring's five rules. By requiring that Part 1 includes the primary regulatory message, it promotes Lord Thring's rules that give precedence to the simpler proposition. And by structuring legislation into three parts, the layered approach complies with the other Thing rules that require division of provisions declaring the law [in Part 1 or 2] with provisions administrating the law [in Part 2 or 3 accordingly]; that principal provisions should be separated from subordinate [in Parts 1 and 2]; that exceptional, temporary, and provisions relating to the repeal of Acts should be separated from the other enactments, and placed by themselves under separate headings [in Part 3]; and that procedure and matters of detail should be set apart by themselves [either in Part 3 of the layered approach, or in a Schedule].

The layered approach seems to be one of the promising initiatives in the field of legislation. But there are three points that need to be clarified. First, the layered approach may, but will not necessarily, lead to a partial, fragmented, or incomplete legislative communication to Heather Cole. There is no doubt that an erroneous application of the approach could result to that. But the placement of the main messages in Part 1 per se must be seen as an added bonus to lay users compared with the current state of affairs: in the layered approach the now frequently elusive main regulatory message will be easily identified, will be brought forward in a pronounced place at the beginning of the legislative text, and will be expressed in a language that is accessible to lay users. Compared to the current state of affairs, where the main message is communicated somewhere within the legislative text and is expressed in the layered approach's Part 2 or 3 language, this is certainly an improvement. And of course, there is nothing preventing Heather Cole from reading the rest of the text: in fact, an inviting Part 1 can only encourage Heather Cole to keep reading, whilst offering her a clear context within which her understanding of complex and detailed messages can only be enhanced.

Second, although Part 1 carrying the main regulatory message is distinctly different from Parts 2 and 3, it may be unclear what really distinguishes between Part 2 data and Part 3 data: both Mark Green and Jane Booker are able to handle complexity and technicality of legislative data. However, they do not both require the same data, as demonstrated by their motives when using www.legislation.gov.uk: Mark Green is interested in answers that allow him to perform his professional but non-legal duties, whereas Jane Booker seeks legal information. As a result, what Mark Green needs is a clear understanding of substantive and procedural requirements imposed by the legislation, whereas Jane Booker seeks deeper 
statutory interpretation often coupled with a holistic view of the statute book. As a result, Part 2 of the layered approach involves answers to questions such as who must do what by when, and what happens if they don't. Part 3 will delve deeper into intricate distinctions and possible exceptions that relate to statutory interpretation and interconnections between legislative texts within the statute book. There are two caveats here. One, Mark Green must still read the text as a whole. And Part 3 cannot be viewed as a mere shell of definitions, repeals, and consequential amendments: this would deprive the readers from at least part of the benefits of the layered approach.

Third, it would be inappropriate to consider that the simplification serviced by the layered approach would result to an abolition of the need for explanatory materials for legislation. In fact, as the layered approach results in an inherent fragmentation of data, it renders the use of explanatory materials and notes reinstating the fluidity of information and the cross-fertilisation between parts an ever so crucial requirement. The new style of explanatory notes introduced by Good Law and showcased in the Armed Forces (Service Complaints and Financial Assistance) Bill [HL] Explanatory Notes enhance the layered approach by introducing a clear table of contents that is thematic rather than provision based, with information on the policy and legal context of the Act, and with simple narratives on the main regulatory messages for all three user groups.

Ultimately, the proof of the layered approach is in its application. User testing can prove whether it works, which user group for, and how it can be amended or fine-tuned to serve users better.

\section{b. Legislative image: presentation, layout, pictures}

Looking now in the image of the legislative text, namely at the picture that the user receives when looking at the text, it is necessary to distinguish between paper and electronic. It is noteworthy that in New Zealand legislation is only published electronically: paper publication ceased last year. In the UK I am not aware of government intent to abolish paper publication or even the tradition of vellum.

Plain language has always advocated the need to rethink the layout of legislative texts. The single font, the lack of adequate contrast between paper and text, the unique format are 
elements of the current legislative image that prevent the user from identifying the important aspects of the regulatory message thus reducing readability of legislative texts. Legislative texts attempt to convey a 'legislative story' to the user, thus allowing them to identify and then understand the underlying policy, the legislative choices made, and the rationale behind the text. This offers them the ability to read and interpret the text in context, thus making accessibility easier and more secure.

The importance of layout has been the main motivation behind the change of legislative layout in the UK in 2001. The current layout shows more white space and a slight change of font coupled with shorter sections and sentences; structure in parts and sections, headings, and the new table of contents [previously known as the table of arrangements] are all tools that promote clearer layout for the purposes of enhancing readability. Specific demonstrations of the modern layout are observed in a number of Acts: the 'step by step' approach to setting out a series of complex rules in section 91 of the Income Tax Act 2007; the tables in section 181 of the Finance Act 2013; the headings for subsections in section 2 of the National Insurance Contributions Act 2014 (Rogers, H, 2015, 56).

However, there is plenty of scope for further progress. Layout is now at the forefront of practitioners' agenda. And quite rightly so. It has been overlooked and there is great scope for change. However, layout alone cannot respond to a complex text, to a complex regulatory message, or indeed to a complex policy. It will contribute to simplification but with the aid of additional visual tools.

One of those tools that have been ignored by even the most visionary of legislative academics and practitioners is the use of image in legislation. Images have been used in legislation that introduces national flags, traffic signs, or planning regulations. But the relationship between picture and legislation has not been explored fully. The visual arts could play a significant role here: there is nothing more direct, relevant to a wide range of users, and time resistant than Cain swinging his club above the prostrate Abel in Titian's painting in Santa Maria della Salute in Venice. The visual representations of themes relating to wrongdoing are so emotionally charged and the characters shown in such magnification that, combined with beauty and other aesthetic values, picture has had tremendous impact on the viewer.

Perhaps the inclusion of images in legislation can enhance the quality of communication. An example could be drawn from criminal provisions. The picture accompanying the legislation in the form of a Schedule may show: 
- what behaviour is to be condemned (show the action; and specify if the person knows that this is bad, suspects that this is bad, or is ignorant of the badness of the behaviour); and

- that this is an offence (for example show a stop sign or show societal disapproval); and

- that it carries a sanction (for example show the penalty and its adverse effect).

The use of typographical and visual aids in legislation can enhance readability immensely. They can address textual limitations and can take the user further by banishing the barriers or written textual communication. User testing is the only way to assess if and how useful they are. But academic research, indeed inter-disciplinary academic research, is the only forum for analysis at a theoretical level first, and then in application to actual legislation.

\section{c. The statute book as a whole}

Reforming the structure and layout of individual legislative texts may bear little fruit without changes in the statute book as a whole. Addressing the issue of legislative volume that enhances complexity has been at the forefront of the agendas of the last two governments as the epicentre of regulatory quality. The volume of legislation came under review in 2003. The Better Regulation Task Force's 'Principles of Good Regulation' linked better regulation with less legislation, and offered a number of regulatory alternatives: do nothing; advertising campaigns and education; using the market; financial incentives; self-regulation and voluntary codes of practice; and prescriptive regulation. In 'The Coalition: our programme for government' the previous government undertook to cut red tape by introducing a 'one-in, one-out' rule whereby no new regulation is brought in without other regulation being cut by a greater amount; and to impose sunset clauses on regulations; and to give the public the opportunity to challenge the worst regulations. Such was the importance attributed to legislative volume that the Prime Minister in his letter of 6 April 2011 to all Cabinet Ministers declared:

'I want us to be the first Government in modern history to leave office having reduced the overall burden of regulation, rather than increasing it.' 
In order to achieve this aim, the UK government went one step further and introduced a onein two-out approach. It undertook to use regulation for the achievement of its policy objectives only where non-regulatory approaches cannot lead to satisfactory outcomes; cost benefits analysis demonstrates a clear margin of superiority of regulation to alternative, self-regulatory, or non-regulatory approaches; or the regulation and the enforcement framework can be implemented in a fashion which is demonstrably proportionate; accountable; consistent; transparent and targeted. The number of Acts passed in 2012 was only 20 with a total number of pages of 1,886: this was a new low after the peak of the late 1990s and early 2000s. But, whilst the number of Acts has decreased since the 1980s, the mean average number of pages per Act has increased significantly, from 37 and 47 pages during the 1980s and 1990s respectively, to 85 in the past decade; if one compares these numbers with the 1950s when the average was 16, a trend of fewer but longer Acts becomes evident. One could contribute this increase to plain language drafting and to the increasing amounts of white space and bigger margins leading to $20 \%$ fewer words on a page. However, there is a crucial contributing factor: over the last 30-40 years the number of Statutory Instruments has steadily increased (Cracknell, R, and Clements, R, 2012, 2). And so the volume of legislation, including primary and delegated, seems to be fighting its ground in practice.

Nonetheless, the UK has been very active in the field of regulatory reform. This is evidenced by a recent OECD Review, which pronounces the regulatory reforms in the UK as impressive (http://www.oecd.org/dataoecd/61/60/44912018.pdf). Points of excellence include the effective balance between policy breadth and the stock and the flow of regulation; and the extensive application of EU's Better Regulation initiatives in the UK.

But of course innovations to the statute book do not end with legislative volume. Blue sky proposals, which in this case may be put to effect much quicker than one might expect, include the current work of The National Archives. John Sheridan leads current thinking both at the theoretical level of viewing the statute book as a collection of big data, and at the application level of presenting a prototype of a radically reformed screen presenting legislation at www.legislation.gov.uk. The Big Data in Law project, led by J. Sheridan, D. Howarth, and H. Xanthaki, revolutionized the way in which the statute book is viewed and led to big data applications and capabilities to UK legislation as a coherent, interrelated, and up to date whole. The project created a search mechanism for researchers allowing them to instigate research on legislation as a body: from the census that allows counting for example the number of 'shall' in UK legislation throughout the years to the introduction of methodology tools that provide 
empirical data on aspects of the statute book or the whole of the statute book. This entirely new and free resource for the research community offers pre-packaged analyses of the data, new open data from closed data, and creates the capability of identifying pattern language for legislation, which would encapsulate commonly occurring legislative solutions to commonly occurring problems thus facilitating legislative communication. The project, which has just concluded, enhances user [in this case researchers'] understanding of the interrelations and interconnections between legislative texts, within fields of law, and across fields of law.

The project feeds into the great efforts led by The National Archives to review the way in which legislation is 'served' to users by offering unprecedented capabilities of identifying relevant legislative texts, such as delegated legislation, cross referenced texts, definitions of terms used in a legislative text, and, in the long term, even case-law clarifying or applying the text to cases. There are already two prototypes of the new screen for legislation. Both have been tested in user testing undertaken by BunnyFoot and including iris trackers as a means of assessing how long a user's eye spends in each part of the text, where the eye is searching for further information and where on the screen, and where the user fails to understand the text or the cross reference completely. This work is of profound importance. What is missing for the purposes of legislative readability is context, and this is what the new screen can provide. This, along with the new format of explanatory notes, can finally offer the user an accurate picture of the labyrinth of legislative data in all their complexity and cross-wiring. Would this facilitate the user? Of course it will: it will depict an accurate image of legislative regulation on the topic searched, thus demonstrating if clear answers can be found or if it is time for the user to accept that statutory interpretation by a trained legal professional is what is really needed in that case.

\section{Conclusions}

The hypothesis of this paper was that legislative quality, and in consequence legislative drafting, is not about words and language. An enlightened approach to legislative drafting proposes that legislative quality is effectiveness of the legislative provision, which is measured by means of the text's ability to produce the desired regulatory results. The paper began with the description of the traditional concept of legislative quality as a means of setting the baseline for debate. The finding of this analysis was that current legislative debate focuses on textual or 
stylistic characteristics of the legislative text. But this framework is based on the misconception that legislative quality is bound by legislative conventions.

As phronetic legislative drafting is infertile ground for rules leading consistently to legislative quality, the paper tackled the second misconception, namely that legislative quality rests in a vacuum. As legislation is a tool for regulation, legislative quality is not an orphan phenomenon. It is part of quality at the legislative and policy levels.

The fluidity of its parameters and its interconnection to law and policy can lead to a third misconception, namely that legislative quality is somehow unachievable or undefinable. The paper defined legislative quality as effectiveness, namely the capacity of the legislative to, with the synergy of the other actors in the policy process, to produce the desired regulatory results.

The paper went on to identify the fourth misconception of legislative quality, namely that effectiveness always lead to it. Apart from the phronetic nature of effectiveness, the paper identified inherent limits of legislation as a product. These are legislation's interconnection and reliance to regulation, the limits of legislation as written communication, and the intrinsic aversion of users to legislative texts.

This analysis led to the identification of the fifth misconception of legislative quality, namely that, in view of the unsurpassable limits of legislative texts, legislative quality should not be pursued further. Tools for further enhancement of legislative quality are the layered structure of legislative texts, the use of image in legislative texts, and the restructuring of the statute book as a whole.

It is hoped that this paper can contribute further to the continuing debate for legislative quality.

\section{Bibiography}

1. Aristotle, E.N., 5.10.1137b13-24.

2. Bennion, F, Bennion on Statute Law (1990, Longman McMillan, London). 
3. Bergeron, R, Rules of Legislative Drafting - Letters to Ukrainian Drafters (1999, Department of Justice Canada and Ministry of Justice of Ukraine, Kiev).

4. Chamberlain, J P, "Legislative drafting and law enforcement" 21 (1931) Am.Lab.Leg.Rev. 235-243.

5. Crabbe, VCRAC, Legislative Drafting (1998, Cavendish Publishing, Oxford).

6. Cracknell, R, and Clements, R, "Acts and Statutory Instruments: the volume of UK legislation 1950 to 2012" HoC Standard Note SN/SG/2911, 15 November 2012.

7. Cranston, R, "Reform through legislation: the dimension of legislative technique" (1978-1979) 73 NwULRev 873.

8. Engle, E, "Aristotle, Law and Justice: the tragic hero" [2008] 35 NKyLRev, 4.

9. Eskridge Jr, W, “Gadamer/Statutory interpretation” [1990] 90 ColumLRev, 635.

10. Flueckiger, A, "Régulation, dérégulation, autorégulation : lémergence des actes étatiques non obligatoires" (2004) 123 Revue de droit suisse 159.

11. Flueckiger, A, "L' évaluation législative ou comment mesurer lefficacité des lois" (2007) Revue européenne des sciences sociales 83.

12. Flyvbjerg, B, Making Social Science Matter: Why social inquiry fails and how it can succeed again", (2001, Cambridge University Press, Cambridge).

13. Jenkins, I, Social Order and the Limits of the Law: a Theoretical Essay (Princeton, Princeton University Press, 1981).

14. Mader, L, "Evaluating the effect: a contribution to the quality of legislation" 22 (2001) Statute Law Review 119-131.

15. Mousmouti, M, "Operationalising quality of legislation through the effectiveness test" (2012) 6 Legisprudence 191.

16. Muller, G, and Uhlmann, F, Elemente einer Rechtssetzungslehre (2013, Zurich, Asculthess).

17. New Zealand Law Commission, Legislative Manual: Structure and Style, New Zealand Law Commission Report No 35 (1996, Wellington).

18. Nutting, C, "Legislative Drafting: A Review" (1955) 41 American Bar Association Journal, 76.

19. OECD Report, "Alternatives to traditional regulation", para 0.3; and also OECD, Regulatory Policies in OECD Countries: From Interventionism to Regulatory Governance (Paris, OECD, 2002).

20. Office of Parliamentary Counsel, "Drafting Guidance”, 2 October 2010, 
21. http://webarchive.nationalarchives.gov.uk/+/http://www.cabinetoffice.gov.uk/media/4 27772/drafting-guidance-101002.pdf, 31.

22. Renton Report (Cmnd 6035) para 13.22.

23. Rideout, C, "Storytelling, narrative rationality, and legal persuasion" [2008] 14 Legal Writing: J. Legal Writing Inst., 75.

24. Rogers, H, 'Good Law: how can the design of Bills and Acts help?' in Design Commission, Designing Democracy: how designers are changing democracy - spaces and processes, An Inquiry of the Design Commission, March 2015, http://www.policyconnect.org.uk/apdig/sites/site_apdig/files/report/497/fieldreportdo wnload/designingdemocracyinquiry.pdf.

25. Rose, A, "Sociological Factors in the Effectiveness of Proposed Legislative Remedies" (1959) 11 J. 470.

26. Scharffs, B G, "Law as Craft” (2001) 45 Vanderbilt Law Review, 2339.

27. Schram, S F, and Caterino, B, Making Political Science Matter: Debating Knowledge, Research, and Method (2006, New York University Press, New York).

28. Snyder, F, “The effectiveness of European Community Law: institutions, processes, tools and techniques" (1993) 56 Mod L Rev 19.

29. Staem, N, “Governance, Democracy and Evaluation” (2006) 12(7) Evaluation 7.

30. Stefanou, C, "Drafters, drafting, and the policy process" in Stefanou, C, and Xanthaki, H, (eds), Drafting Legislation: A Modern Approach - in Memoriam of Sir William Dale, (2008, Ashgate-Dartmouth, Aldershot), 321-332.

31. Teubner, G, "Regulatory law: Chronicle of a Death Foretold" in Lenoble (ed), Einfuhrung in der Rectssoziologie (1987, Darmstadt, Wissenschaftliche Buchgesellschaft).

32. Thring, Lord, Practical Legislation, The Composition and Language of Acts of Parliament and Business Documents (London, 1902).

33. Timmermans, C, "How Can One Improve the Quality of Community Legislation?" (1997) 34 Common Market Law Review 1229.

34. Voermans, W, "Concern about the Quality of EU Legislation: What Kind of Problem, by What Kind of Standards?” (2009) 2 Erasmus Law Review 59.

35. Weatherhill, S, "The challenge of better regulation" in S. Weatherhill (ed.), Better Regulation, (2007, Hart, Oxford and Portland, Oregon) 1-19. 
36. Xanthaki, H, "On transferability of legislative solutions: the functionality test" in C. Stefanou and H. Xanthaki (eds), Drafting Legislation: A Modern Approach - in Memoriam of Sir William Dale, (2008, Ashgate-Dartmouth, Aldershot), pp.1-18.

37. Xanthaki, H, "Drafting manuals and quality in legislation: positive contribution towards certainty in the law or impediment to the necessity for dynamism of rules?" [2010] 4 Legisprudence 111-128.

38. Xanthaki, H, "Duncan Berry: A true visionary of training in legislative drafting” [2011] The Loophole 18.

39. Xanthaki, H, "Quality of legislation: an achievable universal concept or a utopian pursuit?" in Marta Travares Almeida (ed.), Quality of Legislation (2011, Nomos, Baden-Baden), 75-85.

40. Xanthaki, H, Thornton's Legislative Drafting (2013, Bloomsbury, London).

41. Xanthaki, H, "The regulatory reform agenda and modern innovations in drafting styles" in L. Mader (ed.), Regulatory Reform (2013, Nomos, Baden-Baden), 128-142. 